\title{
Sustainability of Open Educational Resources: the eCity case
}

\author{
Carlos Vaz de Carvalho, Paula Escudeiro \\ GILT - Games, Interaction and Learning Technologies \\ Instituto Superior de Engenharia do Porto \\ Porto, Portugal \\ $\{\mathrm{cmc}$, pmo\}@isep.ipp.pt
}

\begin{abstract}
The promotion of Open Educational Resources (OER) as reusable tools for teachers and students is highly relevant but the nature of the income model requires specific strategies to maintain and update those resources. eCity is a city simulation game that supports a Problem Based Learning (PBL) pedagogical methodology in secondary schools and, at the same time, fosters the interest of students in following an Engineering career. The game is freely available through online stores and the generated interest (about $\mathbf{1 0 0 . 0 0 0}$ downloads so far) has raised the need to discuss and adopt a sustainability strategy for the maintenance of the game and the development of new versions. This article presents possible alternatives for that strategy.
\end{abstract}

Keywords - open educational resources, sustainability, serious games, educational games, problem based learning

\section{INTRODUCTION}

The concept of Open Educational Resources (OER) refers to "technology-enabled, open provision of educational resources for consultation, use and adaptation by a community of users for non-commercial purposes", according to UNESCO's definition [1]. Or OER are "digital learning resources offered online freely and openly to teachers, educators, students, and independent learners in order to be used, shared, combined, adapted, and expanded in teaching, learning and research" [2]. These are two very broad definitions (although the second one does force its application only in the online digital domain) leaving a lot of room for further detailing the concept. For instance, what does "open" imply? Does it mean that anyone can access and change the source of the resource (accessing the editable .docx or .pptx files, for instance) and make changes or users are just allowed to reuse static .pdf files "as is"? And what does "adaptation" mean? Do users have access to the code of educational games and applications and change it (creating, in fact, new applications) or are they just allowed to "MOD" them, that is, creating new scenarios, characters or maps that are integrated in the game? For instance, for the European OER Policy Project that supports the adoption of OER policies in Europe and advocates that all educational content (textbooks and other educational materials, including educational games) that is being produced in Europe with public funding should be available for free, that is what "open" and "adaptable" means [3]. Licensing schemes are relevant tools to define the extent of "open", "use", "adaptation", "share" and all related concepts.

Understanding these aspects is fundamental to address the OER sustainability issue. The promotion of OER as reusable tools for teachers and students is highly relevant but the nature

\author{
Manuel Caeiro Rodríguez, Martín Llamas Nistal \\ Departamento de Ingeniería Telemática \\ Universidad de Vigo \\ Vigo, Spain \\ \{mcaeiro,martin\}@det.uvigo.es
}

of the supporting financial and delivery models requires specific strategies to maintain and update those resources once they normally do not directly generate income.

The sustainability of OERs is mostly related to finding ways to allow its continued use and reuse by teachers, learners and/or other educational stakeholders although some authors include also the actual cost of producing the contents as part of sustainability issue. For instance, Pegler identified several general aspects related to sustainable OER practice [4]:

- The acknowledgement of the time and effort required to create sustainable OER and therefore the creation of guides for potential producers and users.

- The buildup of academic awareness and recognition towards OER.

- The creation of incentives for sector wide sharing.

- The existence of evidence of OER effectiveness.

- The availability of easy to use tools for dissemination and deposit.

- The setup of policies to encourage and offer reward to "open" behavior, including support and advice on copyright issues and potential risk management.

In the scope of this article, we are mostly concerned with costs related to maintaining and updating existing OER. These costs are related to delivery channels (servers, fees to use online stores, etc.), to the adaptation of the OERs to changes in support platforms (like new OS versions), to localize OERs, to produce new content, etc. Depending on the OER project size and on the support organization, Wiley presented several funding models [5] following Downes' presentation [6]

- Endowment model - the project obtains base funding and lives upon interest earned on that fund.

- Membership or fee model - a coalition of interested organizations and/or individuals are invited to contribute a certain sum, either as seed only or as an annual contribution or subscription.

- Donations model - when a project requests and receives donations by the community.

- Conversion, segmentation or freemium model - when base services or contents are available for free but paying subscribers receive additional or advanced features. 
- Sponsorship model - when companies support OER projects on a more or less explicit sponsorship basis.

- Institutional model - when an institution assumes the responsibility for an OER initiative.

- Governmental model - similar to the institutional model, the governmental model represents direct funding by government or even extra-government entities.

- Replacement model - the educational content stored, disseminated, and re-used through OER often replaces the use of other technology, software and infrastructure so the cost savings resulting from their discontinued use can be employed to fund the OER production and maintenance.

- Voluntary support model - a revenue model based on voluntary support and activities, namely through setting up communities of practice (even virtual ones).

The assumption of one (or several) of these models depends on a careful analysis of the OER in question, its authors and supporting organizations. This was the case of eCity (http://ecity-project.eu), a city simulation game meant to support a pedagogical methodology that stimulates the integration and continuous exploitation of Problem Based Learning (PBL) in secondary schools and, at the same time, intended to foster the interest of school students in following a career in Engineering [7].

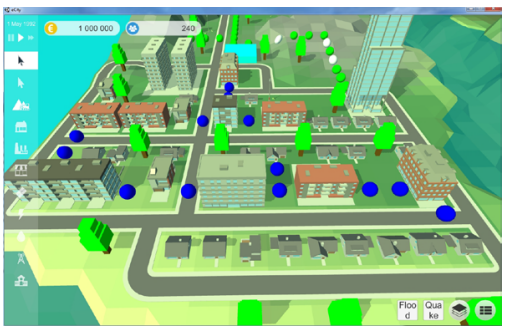

Fig. 1. The eCity Game

The game was developed in the scope of a European Lifelong Learning Programme (LLP) project and was grounded on the identified difficulty that secondary education students have with Mathematics and other Science topics which later prevents them from following a technical or scientific academic path. The project assumed that this was not due to lesser skills of these youngsters but mostly due to wrong teaching strategies. Students belong to the "net-generation" and they are "digital natives": they are technologically-savvy, they quickly absorb information but in shorter chunks, they expect instant responses and feedback and they want to be active in their learning [8] Games have been demonstrated to be particularly fit for experiential learning and to support competence development for engineering [9][10] so there was a clear fit to the project objectives.
The main result of the project, the game, is now freely available in online stores and has been already downloaded about 100,000 times. This demonstrates how well it has been received by the target audience and raises very interesting prospects in terms of exploitation so there was the need to identify possible strategies and models to support its sustainability (and the one of the associated products) including the provision of copyright issues and licensing schemes. This article presents that discussion as a way to foster the debate on the subject.

\section{LICENSING OER}

OER are frequently reused "as-is" (that means without any change) either because users don't have the technical ability to edit the resources or they don't have the rights to do it. However teachers do like to make changes to existing resources to make them better fit to their course curricula. For instance they might break up long presentations so that they fit the length of a lecture or so that they can be used to support group activities. Or localization changes can be made to allow for usage in specific cultural contexts. User annotations are also a form of adapting/changing those contents.

Licensing schemes define all the possibilities for the use and exploitation of the educational resources as established by the resource owner (normally also the author). In this context it is important to compare Creative Commons (CC) licensing scheme (suitable to the eCity associated results) to specific free software licenses more adjusted to the nature of the eCity game.

\section{A. Creative Commons}

Creative Commons is a nonprofit initiative that offers free, easy-to-use copyright licenses to specify which rights to reserve and which rights to waive about a piece of work [11]. CC allows users to search, share, use and adapt, in full legality, hundreds of millions of works - from songs and videos to scientific and academic material. All Creative Commons licenses follow a set of basic principles:

- Credit the creator;

- Provide the title of the work;

- Provide the URL where the original work is hosted;

- Indicate the type of license it is available under and provide a link to the license terms;

- Keep intact any copyright notice associated with the work.

Table I shows the CC licenses in version 4.0. This set of CC licenses extends from the most restrictive approach, prohibiting any type of usage for the resources, to the most permissive option by offering the resource to the public domain, allowing users to change the original content and distributing those changes. 
TABLE I. CREATive COMMONS LiCEnSES [11]

\begin{tabular}{|c|c|c|c|}
\hline & & $\begin{array}{c}\text { Commercial } \\
\text { use? }\end{array}$ & $\begin{array}{l}\text { New versions } \\
\text { can be created? }\end{array}$ \\
\hline $\begin{array}{l}\text { Attribution } \\
\text { CC-BY }\end{array}$ & (cc) (i) & & \\
\hline $\begin{array}{l}\text { Attribution- } \\
\text { ShareAlike } \\
\text { CC BY-SA }\end{array}$ & (c) (i) () & & 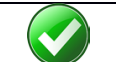 \\
\hline $\begin{array}{l}\text { Attribution- } \\
\text { NoDerivative } \\
\text { s CC BY-ND }\end{array}$ & (cc) (†) & & \\
\hline $\begin{array}{l}\text { Attribution- } \\
\text { NonCommerc } \\
\text { ial CC BY- } \\
\text { NC }\end{array}$ & (cc) (1) \& & & licensed as \\
\hline $\begin{array}{l}\text { Attribution- } \\
\text { NonCommerc } \\
\text { ial- } \\
\text { ShareAlike } \\
\text { CC BY-NC- } \\
\text { SA }\end{array}$ & (cc) & & $\begin{array}{c}\text { licensed as CC } \\
\text { BY-NC-SA }\end{array}$ \\
\hline $\begin{array}{l}\text { Attribution- } \\
\text { NonCommerc } \\
\text { ial-NoDerivs } \\
\text { CC-NC-ND }\end{array}$ & (c) & & \\
\hline
\end{tabular}

B. Software licenses FSF and OSI

In the case of software licenses the most relevant proposals are the ones from the Free Software Foundation (FSF) and from the Open Source Initiative (OSI).

The Free Software Foundation (FSF) is a foundation that seeks to promote the development and use of free software. The foundation's mission is "to preserve, protect and promote the freedom to use, study, copy, modify, and redistribute computer software, and to defend the rights of free software users" [12].

The Open Source Initiative (OSI) is an organization dedicated to the promotion of open source. The organization defines itself as a "...global non-profit organization that promotes and supports the open source movement." Among other things, the organization maintains a list of licenses that comply with that definition [13].

According to FSF, an application is free software if the users have four essential freedoms [12]:

- The freedom to run the program as they want, for any purpose (freedom 0 ).

- The freedom to study how the program works, and change it as they want (freedom 1). Access to the source code is a precondition for this.

- The freedom to redistribute copies so that the user can help other users (freedom 2).
- The freedom to distribute copies of the modified versions (freedom 3). Access to the source code is a precondition for this.

The General Public License (GPL) is a FSF license that allows end users to freely use the software in addition to studying, copying and modifying it (also called copyleft) [13].

An application must also meet certain requirements to be considered open source [14]. These requirements are consistent and extend the four freedoms of free software:

\section{Free Redistribution.}

2. Access to Source Code.

3. Creation of Derived Works.

4. Integrity of the Author's Source Code.

5. No Discrimination Against Persons or Groups.

6. No Discrimination Against Fields of Endeavour.

7. Distribution of License.

8. License Must Not Be Specific to a Product.

9. License Must Not Restrict Other Software.

10. License Must Be Technology-Neutral.

\section{ECITY SUSTAINABILITY}

The funding model of the eCity game (and related products) relied initially on the government model, through a grant from EACEA, the Education, Audiovisual and Culture Executive Agency, the entity responsible for managing several European Union's programmes on these areas. This initial funding supported the creation, testing and validation of the eCity products and their initial delivery. A post-grant sustainability strategy for eCity had to be thought, prepared and implemented while the products were being created and tested. Options considered were the freemium model (keeping the existing versions free and releasing new versions with paid services) and the voluntary support model. In either cases, an extended used adoption would be required so a continuous valorization process was organized, together with several pilot implementation and exploitation events. The idea was somehow to follow Wiley's idea of creating communities of users, learning and practice [5] that could, through interaction, sharing and socializing, promote the use of the game and related tools.

\section{A. Market Analysis}

A search for existing projects related to the eCity concept was conducted to analyze best practices about the use of games in PBL and engineering education.

In this context, urban simulation was intended to model the development of an urban area, reflecting the most important features that conditions/fosters that development. Urban simulators are used in the most diverse contexts and environments, from professional urban planning and sociological studies to games. In the context of the eCity project urban simulation is used as a game environment that supports 
the setup and resolution of problems and challenges to be used in the context of PBL.

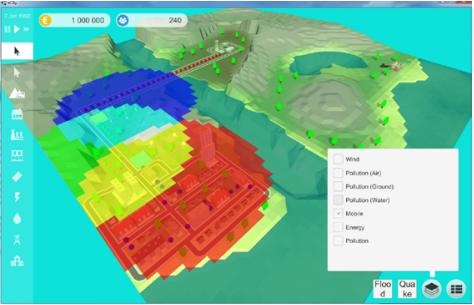

Fig. 2. Mobile antenna placement problem in eCity

Therefore it was important to analyze existing urban simulation games and platforms for the development of urban simulation to assess their suitability for the project objectives. The main conclusion from the 12 games assessed was that some exemplary cases existed, like the SimCityEdu approach (http://www.simcityedu.org/) but none covered the full scope of eCity's objectives at least in terms of the learning/serious purposes, as reported in [15].

\section{B. Dissemination and valorization}

The project dissemination approach was designed to increase the range of adopters of the materials by creating early interest in the contents and methodology. The dissemination focused, on one side, on Engineering Education entities and secondary/vocational schools to promote the methodology and, on another side, on the general public for awareness raising. Education authorities and educational deciders were also addressed by specific dissemination events. One of the largest engineering associations in the world, the IEEE, has been involved, as an associate partner, through the Portuguese and Spanish chapters of its Education Society. Other national engineering associations and Higher Education networks were also involved. The main dissemination actions were:

- Creation and maintenance of the Project Web Site (including information on the project, objectives, methodology, partnership and results). The web site was translated in eight different languages. In the end the website reported over 250,000 hits.

- Creation and distribution of an electronic newsletter with periodic updates and information sent to all the registered users from the web site but also to teachers and engineering education entities. The final list of newsletter recipients was about 2600 individuals and entities.

- Creation \& distribution of flyers, brochures, booklets and other elements for publicity and image promotion. About 2,500 physical elements were distributed in conferences, workshops and other events. This includes dissemination outside of the European scope, in Asia and South and North America.
- Publication of articles and presentations in conferences and seminars reaching about 1,750 participants.

- Contact with media and press reaching over 1 million viewers all over Europe.

- Contact with engineering education authorities and engineering professional associations representing more than 50,000 engineers.

- Presentation of the eCity game to Serious Games Associations, reaching over 1,500 members.

\section{Piloting}

The piloting was carried out in 5 different countries: Portugal, Greece, Spain, Turkey, and Italy with a view to test but also to valorize the project results. The testing included students enrolled in upper secondary level courses in vocational high schools and students enrolled in post-secondary level courses in higher technical institutes and universities. In total there were 1,240 students involved in the testing, 885 from the uppersecondary level institutes and 355 from the post-secondary level institutes. Around 150 teachers took part in the testing, in focus groups and interviews.

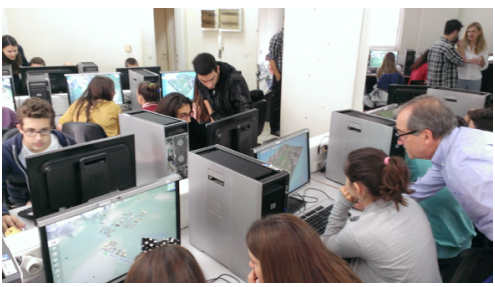

Fig. 3. Students piloting eCity game in Volos, Greece

The majority of the students involved in testing were secondary (and vocational) school students $(71 \%)$ in comparison to $29 \%$ of higher education students. The reason is that the platform was primarily aimed at high school students, also in terms of the content, to attract them to study engineering subjects and to motivate them into choosing a university engineering path after high school. The higher education students accounted for a research sample that can provide relevant feedback in terms of the adaptability of the software for higher age groups, and suggestions on its possible use and adaptations for higher education levels. Secondary education students were monitored by their teachers and, in some cases, by university students involved in tutoring assignments. Sessions lasted, on average, from 2 to 2:30 hour, giving the students enough time to test 2 scenarios per session.

The assessment methodology gathered the feedback of the final users through a holistic approach in the evaluation of the platform aspects. The feedback gathered from the end users was used to implement the final version of the game and was therefore considered essential for the successful implementation in formal and non-formal learning environments. 
For all the students interviewed, it was evident that a convincing majority $(65.08 \%)$ found the game fun or very fun to play, and only $11.69 \%$ found it little or not interesting to play. The satisfaction shown by the students was due to a number of positive aspects: the possibility to approach real life representative problems and solve them, the simplicity of the game controls, the feeling of "reality" of the game, an entertaining, fresh approach to study school subjects, the ability to control the results of their actions and the immediate feedback on choices. One of the most rewarding aspects of the game was the feeling of having to "put the mind to work" and use all individual resources and knowledge.

The $11.69 \%$ poor satisfaction level can be attributed to the fact that some students were impatient when trying to solve the game, not taking enough time to study the game, the objectives and options available so they often found themselves losing the game after a short while. Some also commented on the fact that computer games were not "their sort of entertainment", not something they usually enjoy or use as a pastime.

In general though, most of the students believed that the game was fun to play and enjoyable to replay. They found the game like an alternative activity to do during their classes and in their free time, that can be beneficial for their learning process. There was also a positive feedback from the teachers that were playing the game as passionately as the students, especially those teaching STEM subjects. They recognized the potential of eCity to be used in the classroom. Both students and teachers expressed the desire to have access to the eCity platform and the possibility of having it on their smartphones.

When it comes to the comparison between male and female users, the numbers show a higher interest by the male users, but only for a small difference. Only $9.00 \%$ of the male users found the game little or no satisfying at all, in comparison to $17.96 \%$ of the female users. This ratio of the interest in the nature of this game is equivalent to the misbalance of the interest of female and male population in engineering and STEM subjects in general, that has tended to be in favor of the male population. However, the results show that also the female students have a solid interest in the game, $54.95 \%$ of the female participants denoting the platform is fun or very fun to use. This confirms the general trend in serious game playing that shows that games for learning tend to appeal to both males and females.

\section{DISCUSSION}

The consortium selected which of the project results would be most valuable as OER and discussed the individual licensing and corresponding openness:

1. The eCity game binary executable (or equivalent) files in its version 1.5.1, available for Windows, MacOs and Linux operating systems will be available for free, inside and outside the consortium. No commercial use will result from this component. New scenarios can be created by the teachers and can be automatically uploaded to the server without human intervention. An embedded rating system is in place to filter and clean the list of scenarios. The eCity source files are treated as confidential by project partners and shall not be distributed outside the consortium. As such the City game will allow users Freedom 0 and Freedom 2.

2. The pedagogical guidelines for teachers that explain and provide examples of use of the game are freely available (including sources) under the Attribution-NonCommercial CC BY-NC licensing scheme which allows to use, share and edit but not for commercial purposes.

3. The resources (3D models, animations, graphics, images, fonts, algorithms, etc.) embedded in the eCity game have been acquired externally and thus cannot be shared accordingly to the original license.

Finally, the selected funding model to support project results was the conversion, segmentation or freemium model where base services and contents are available for free but paying subscribers receive additional or advanced scenarios and problems to use in their classrooms. Potentially this model can be combined with the governmental model. The potential fixed costs for this model are the following:

- Delivery platform for the different game versions with a reasonable bandwidth, backup insurance. Includes a server to host new scenarios created by the teachers. The cost relates to a commercial provider hosting the platform ( 250 $€ /$ year) plus the generation of new versions of the game required due to technology changes $(500 €)$.

- New scenarios can be created by consortium members to focus on specific issues or problems. These scenarios can be distributed freely or based on a fee scheme $(2,500 €)$.

- New versions and uploads required due to distribution to new platforms $(2,500 €)$

- Update of game elements, adding new models, graphics, images, etc. and adjusting the simulation engine accordingly $(25,000 €)$.

Potential revenue sources to support those costs are the following:

- Scenario fees resulting from the use of paid scenarios whenever created by the partners. This covers all the optional costs related to the production of new scenarios and new platform versions $(5,000 €)$.

- Funding from public programmes or government entities $(50,000 €)$

\section{CONCLUSIONS}

eCity is a city simulation game meant to support a pedagogical methodology that stimulates the integration and continuous exploitation of Problem Based Learning (PBL) in secondary schools and, at the same time, to foster the interest of school students in following a career in Engineering. The main result of the project, the game, is now freely available in online stores and has been already downloaded about 100,000 times. eCity is also recommended by the Turkish and the Greek Education Ministry as an educational resource and is available at the Scientix repository, the European central repository for Science related educational contents. 
This demonstrates how well eCity was received by the target audience and raised very interesting prospects in terms of exploitation so there was the need to identify possible strategies and models to support its sustainability (and the one of associated products) including the provision of copyright issues and licensing schemes.

The final decision was to adopt the conversion, segmentation or freemium model where base services and contents are available for free but paying subscribers receive additional or advanced scenarios and problems to use in their classrooms. Potentially this model can be combined with the governmental model through grants. Hopefully, this model will allow eCity to continue to be supported and updated in the next few years.

\section{ACKNOWLEDGEMENT}

Part of this work was financed by the European Commission under the Lifelong Learning Programme, KA3 action, Project eCity, ref. 543573-LLP-1-2013-1-PT-KA3-KA3MP and by the RIURE-NET project, funded by the CYTED programme.

\section{REFERENCES}

[1] UNESCO, "UNESCO Promotes New Initiative for Free Educational Resources on the Internet", retrieved from: http://www.unesco.org/education/news en/080702 free edu ress.shtm 1

[2] J. Hylén, D. V. Damme, F. Mulder, S. D'Antoni, "Open Educational Resources: Analysis of Responses to the OECD Country Questionnaire", OECD Education Working Papers, No. 76, OECD Publishing. 2012, http://dx.doi.org/10.1787/5k990rjhvtlv-en

[3] A. Tarkowski, European Open Educational Resources Policy Project, retrieved from: https://wiki.creativecommons.org/wiki/European OER Policy Project

[4] G. Pegler. How can we achieve sustainability in OER? Retrieved from http://www8.open.ac.uk/score/print/oer-and-sustainability-leedsmanifesto-draft;

[5] D. Wiley, "On the Sustainability of Open Educational Resource Initiatives in Higher Education", Retrieved from: http://www.oecd.org/edu/oer

[6] S. Downes. Models for Sustainable Open Educational Resources. (A. Koohang, Ed.), Interdisciplinary Journal of Knowledge and Learning Objects , 3. 2007

[7] M. Rodríguez Bermúdez, M. Caeiro Rodríguez, M. Llamas Nistal, C. Vaz de Carvalho and F. Nogueira, "eCity: Virtual city environment for engineering problem based learning," 2015 IEEE Global Engineering Education Conference (EDUCON), Tallinn, 2015, pp. 159-166. doi: 10.1109/EDUCON.2015.7095966

[8] R. Batista and C. Vaz de Carvalho, "Work in progress - learning through role play games," 38th Annual Frontiers in Education Conference, Saratoga Springs, NY, 2008, pp. T3C-7-T3C-8. doi: 10.1109/FIE.2008.4720599

[9] D. Gouveia, D. Lopes, C. Vaz de Carvalho, "Serious Gaming for Experiential Learning", Proceedings of FIE - IEEE Frontiers in Education Conference, Rapid City, South Dakota, October 12 - 15, 2011 (IEEE Catalog Number: CFP11FIE-USB, ISBN: 978-1-61284-467-1)

[10] C. Vaz de Carvalho, "Is Game-Based Learning Suitable for Engineering Education?", Proceedings of the EDUCON 2012 - Third IEEE Global Engineering Education Conference, Marrakesh, Morocco, 17-20 April 2012, ISBN: 978-1-4673-1456-5

[11] Creative Commons, "About", Retrieved from: https://creativecommons.org/about/

[12] Free Software Foundation, "About". Retrieved from http://www.fsf.org/about

[13] Free Software Foundation, "A Quick Guide to GPLv3", Retrieved from: http://www.gnu.org/licenses/quick-guide-gplv3.html

[14] Open Source Initiative, "About". Retrieved from: https://opensource.org/about

[15] Manuel Caeiro Rodríguez, Martín Llamas Nistal, Melisa Rodríguez Bermúdez, Carlos Vaz de Carvalho, "eCity Environment Specification", Technical Report of the eCity Project, Retrieved from: http://ecityproject.eu/site/assets/files/1/wp3 specification report v8.pdf 